\title{
Medical Image of the Week: Saber Sheath Trachea
}
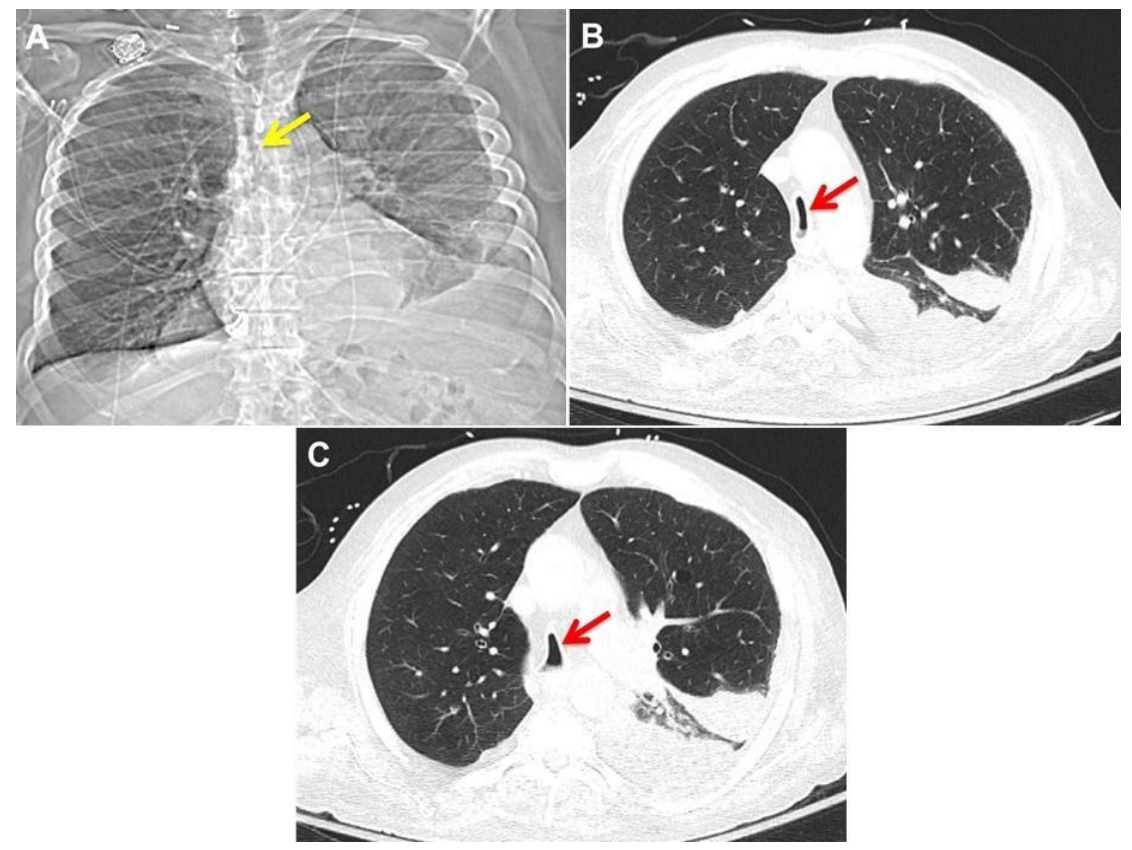

Figure 1. A: Narrowing in the mid and lower parts of the trachea on the scout film (arrow). B: Cross sectional image from chest computed tomography (CT) showing coronal narrowing of the trachea (arrow). C: Cross sectional images from chest computed tomography (CT) showing sagittal widening of the trachea (arrow). No mass or external compression seen.

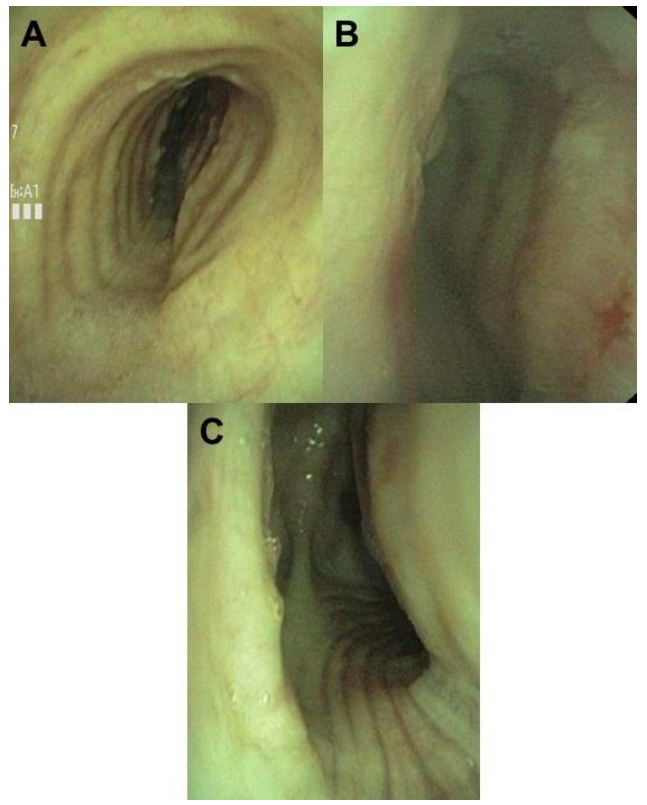

Figure 2. Bronchoscopy image that shows the coronal narrowing and sagittal widening of the $(\mathrm{A})$ proximal trachea, $(\mathrm{b})$ mid trachea and $(\mathrm{C})$ distal trachea. 
A 79-year-old man with chronic obstructive pulmonary disease (COPD) and an active smoker was transferred for evaluation of tracheal narrowing and concerns of malignant external compression versus tracheobronchomalacia for possible stenting.

The patient underwent both chest computed tomography (Figure 1) and bronchoscopy (Figure 2) that confirmed the diagnosis of saber-sheath trachea and ruled out external compression. The airway was still adequately patent during inspiration and expiration with no clear dynamic collapse.

Saber-sheath trachea is commonly described as intra-thoracic coronal narrowing and sagittal widening of the trachea (like a sword sheath). Repetitive cartilaginous injury from excessive coughing and elevated intra-thoracic pressure causes degeneration and calcification of the trachea cartilage, leading to remodeling and bending of the tracheal cartilage (1). Presence of saber-sheath trachea is highly associated with obstructive lung disease, which is present in our patient (2). There is no known specific treatment for saber-sheath trachea, however if patient with saber-sheath trachea were to require intubation, air leak can be a concern due to the rigid deformity of the trachea (3).

See-Wei Low, MD'; Huthayfa Ateeli, MD²; James Knepler, $\mathrm{MD}^{2}$

${ }^{1}$ Department of Internal Medicine and ${ }^{2}$ Pulmonary, Allergy, Critical Care and Sleep Medicine Banner University Medical Center Tucson Tucson, AZ, USA

\section{References}

1. Ismail SA, Mehta AC. "Saber-sheath" trachea. J Bronchol Intervent Pulmonol 2003;10:296-7. [CrossRef]

2. Greene R. Saber-sheath trachea: relation to chronic obstructive pulmonary disease. AJR Am J Roentgenol. 1978;130:441-5. [CrossRef] [PubMed]

3. Wallace $E$, Chung F. General anesthesia in a patient with an enlarged sabersheath trachea. Anesthesiology. 1998;88:527-9. [CrossRef] [PubMed] 